\title{
Chloride adsorption by calcined layered double hydroxides in hardened Portland cement paste
}

\author{
Seyoon Yoon ${ }^{\mathrm{a}}$, Juhyuk Moon ${ }^{\mathrm{b}, *}$, Sungchul Bae ${ }^{\mathrm{c}}$, Xiaonan Duan ${ }^{\mathrm{d}}$, \\ Emmanuel P. Giannelis ${ }^{\mathrm{d}, \mathrm{e}}$, Paulo M. Monteiro ${ }^{\mathrm{c}}$ \\ ${ }^{a}$ School of Engineering, Kings College, University of Aberdeen, Aberdeen AB24 3UE, UK \\ ${ }^{\mathrm{b}}$ Civil Engineering Program, Department of Mechanical Engineering, State University of New York at Stony Brook, New York 11794, USA \\ ${ }^{c}$ Department of Civil and Environmental Engineering, University of California, Berkeley, CA 94720, USA \\ d Department of Materials Science and Engineering, Cornell University, Ithaca, NY 14853, USA \\ ${ }^{\mathrm{e}}$ Center for Refining and Petrochemicals, The Research Institute, King Fahd University of Petroleum and Minerals, Dhahran 31261, Saudi Arabia
}

\section{H I G H L I G H T S}

- We examine the adsorption equilibrium and kinetics of CLDH in the hydrated cement.

- CLDH capacity to bind chloride ions in the hydrated cement paste is determined.

- We model chloride adsorption by CLDH through the cement matrix.

- CLDH reforms the layered structure with ion adsorption in the cement matrix.

\section{A R T I C L E I N F O}

\section{Article history:}

Received 4 September 2013

Received in revised form

10 January 2014

Accepted 13 February 2014

\section{Keywords:}

A. Composite material

D. Diffusion

D. Corrosion

D. Adsorption

\begin{abstract}
A B S T R A C T
This study investigated the feasibility of using calcined layered double hydroxides (CLDHs) to prevent chloride-induced deterioration in reinforced concrete. CLDHs not only adsorbed chloride ions in aqueous solution with a memory effect but also had a much higher binding capacity than the original layered double hydroxides (LDHs) in the cement matrix. We investigated this adsorption in hardened cement paste in batch cultures to determine adsorption isotherms. The measured and theoretical binding capacities (153 $\mathrm{mg} \mathrm{g}^{-1}$ and $257 \mathrm{mg} \mathrm{g}^{-1}$, respectively) of the CLDHs were comparable to the theoretical capacity of Friedel's salt $\left(2 \mathrm{~mol} \mathrm{~mol}^{-1}\right.$ or $\left.121 \mathrm{mg} \mathrm{g}^{-1}\right)$, which belongs to the LDH family among cementitious phases. We simulated chloride adsorption by CLDHs through the cement matrix using the Fickian model and compared the simulation result to the X-ray fluorescence (XRF) chlorine map. Based on our results, it is proposed that the adsorption process is governed by the chloride transport through the cement matrix; this process differs from that in an aqueous solution. X-ray diffraction (XRD) analysis showed that the CLDH rebuilds the layered structure in a cementitious environment, thereby demonstrating the feasibility of applying CLDHs to the cement and concrete industries.
\end{abstract}

Crown Copyright $\odot 2014$ Published by Elsevier B.V. All rights reserved.

\section{Introduction}

Steel embedded in concrete is normally protected by a passive film formed by a thin iron oxide layer on the steel surface, which remains stable due to the high-alkaline environment of the cement-based materials. Corrosion can initiate when this protective film is depassivated by chloride attack in the saline

\footnotetext{
* Corresponding author.

E-mail addresses: juhyuk.moon@stonybrook.edu, jmoon3081@gmail.com
} (J. Moon). environment $[1,2]$. The corrosion of steel reinforcing bars due to chloride attack usually affects reinforced concrete (RC) structures exposed to de-icing salts, unwashed sea sand, or seawater, and may cause the major deterioration of the structure [3]. To address this issue, many protecting inhibitors against chloride attack have been developed. They can be classified according to their application methods: (1) added to fresh concrete as an admixture; and (2) applied on the surface of hardened concrete or the steel reinforcing bars [4]. Many materials, such as sodium nitrite and aminoalcohol, have been used as admixed or surface-applied inhibitors against corrosion in reinforced concrete [5,6]. Such inhibitors usually cover the anodic or cathodic sites of the steel bars to prevent chloride 
attack. A more effective and direct approach would be to find an effective chloride absorbent that works in the cementitious environment.

Because of their high anion exchange capacities, there is an increasing interest in the application of layered double hydroxides (LDHs) to concrete. Hydrotalcite or LDH-like phases found in hydrated slag cement have been demonstrated to increase the binding capacity of chloride ions [7,8]. Tatematsu and Sasaki [9] admixed a hydrocalumite-like material to cement mixtures as a salt adsorbent, and Raki et al. [10] demonstrated that LDH-like materials admixed in concrete can control the release rate of organic admixtures. Furthermore, several methods have been developed to utilize LDH-like phases in the construction industry [11-16], including hydrocalumite- or hydrotalcite-based admixtures to capture chloride and mortars containing hydrocalumite, which is used to repair RC structures. The thermal decomposition of $\mathrm{Mg} / \mathrm{Al}-\mathrm{CO}_{3} \mathrm{LDH}$ at around $500{ }^{\circ} \mathrm{C}$ results in $\mathrm{Mg} / \mathrm{Al}$ oxides that increase the binding capacity of anions under the reconstruction of hydrotalcite structures $[17,18]$. For this reason, calcined layered double hydroxide (CLDH) has been employed as a chloride absorbent in aqueous solution $[19,20]$, as expressed by the following equation:

$$
\begin{aligned}
& \mathrm{Mg}_{1-x} \mathrm{Al}_{x} \mathrm{O}_{1+x / 2}+x \cdot \mathrm{Cl}^{-}+(m+1+x / 2) \\
& \mathrm{H}_{2} \mathrm{O} \rightarrow \mathrm{Mg}_{1-x} \mathrm{Al}_{x}(\mathrm{OH})_{2} \mathrm{Cl}_{x} \cdot m \mathrm{H}_{2} \mathrm{O}+x \cdot \mathrm{OH}^{-}
\end{aligned}
$$

Therefore, this CLDH may have the potential to be an effective adsorbent for chloride ions in the cement matrix. Although chloride uptake by CLDH has been carefully investigated in aqueous solutions, the investigation of its adsorption in cementitious materials has not been studied in depth. For this reason, a detailed study of the effect of the cementitious environment on chloride adsorption by CLDH is necessary long overdue.

The primary objective of this study is to provide information to assess the plausible use of CLDH to prevent chloride-induced deterioration in RC structures. Therefore, the equilibrium and kinetics of chloride uptake by CLDH cast in cement pastes were investigated to determine the adsorption isotherms for cementitious systems. To understand the adsorption process in the cement matrix, which might be different from that in aqueous solution based on the adsorption rate and a Fickian diffusion model, the chloride adsorption in the cement matrix was simulated and then compared with an X-ray fluorescence (XRF) map. Through the use of X-ray diffraction (XRD) and scanning electron microscope (SEM), the present study examined whether the cementitious system influenced the structural reconstruction of LDH and its morphology in a similar manner as when CLDH reforms their original layered structure in aqueous solutions.

\section{Literature review}

\subsection{Adsorption of chloride ions by cementitious phases}

Chloride ions interact with cementitious phases in various ways, at times causing phase transitions due to adsorption or ion exchange. The recent review study written by Glasser et al. [21] showed that the binding mechanisms of chloride to the hydrated phases of Portland cement can be mainly classified into two categories: (1) an interaction of chloride ions in the pore solution with calcium silicate hydrate $(\mathrm{C}-\mathrm{S}-\mathrm{H})[22-24]$; and (2) a reaction between chloride ions and AFm phases $[25,26]$. Especially, the AFm phases belong to the lamellar double hydroxide (LDH) large family, and they serve as an important "sink" for chloride ions.

The AFm phase consists of a positively charged main layer $\left[\mathrm{Ca}_{2} \mathrm{Al}(\mathrm{OH})_{6}\right]^{+}$and a negatively charged interlayer $\left[X \cdot n \mathrm{H}_{2} \mathrm{O}\right]^{-}$or ${ }^{2-}$ where $X$ can be either a monovalent or a divalent anion. Studies suggest that Friedel's salt formation is the result of chloride reacting with the AFm phases [26-28]. The previously reported NMR study indicates that dissolution/precipitation and ion exchanges are the main mechanisms in the formation of Friedel's salt by adsorbing chloride ions [26]. In ion exchange, anions are released into the pore solution due to chloride binding by the AFm phases.

$[R-X]+\mathrm{Cl}^{-} \leftrightarrow[R-\mathrm{Cl}]+X^{-}$or $\frac{1}{2} X^{2-}$

where, $R$ indicates the ion exchange sites. However, a chloro-sulfate AFm phase, known as Kuzel's salt, has also been identified [28-30]. Chloride readily displaces sulfate from calcium monosulfoaluminate $\left(\mathrm{SO}_{4}-\mathrm{AFm}\right)$, which is in solid solution with hydroxyl $\mathrm{AFm}$, thus forming an intermediate compound Kuzel's salt $\left(\mathrm{Cl} / \mathrm{SO}_{4}-\right.$ AFm) at low chloride concentration but Friedel's salt ( $\mathrm{Cl}-\mathrm{AFm})$ at higher chloride concentration above molar ratio $\mathrm{Cl} / \mathrm{Al} \sim 0.70$ $[28,30,31]$. Sulfate ions released from calcium monosulfoaluminate, form ettringite and this additional ettringite formation results in a significant increase in the molar volume of the solids.

Despite the complex chloride-binding phenomenon, various assumptions and simplifications can be found in the literature with regard to the description of chloride binding by AFm phases $[21,30,32]$. At equilibrium and in saturated conditions, the most common and simple way to describe chloride-matrix interactions is to use an analytical formula, which is Langmuir's or Freundlich's isotherm. The Nernst-Planck/Poisson model was developed to model the chloride ingress [33-38], and it can include these analytical formulas to estimate the bound chloride content during ionic transport through cement-based materials. Tang and Nilsson have shown that Langmuir's equation is more appropriate within the low free chloride concentration range $\left(<0.05 \mathrm{~mol} \mathrm{~L}^{-1}\right)$ and that Freundlich's equation offers a better fitting within the high free chloride concentration range $\left(>0.01 \mathrm{~mol} \mathrm{~L}^{-1}\right.$ ) [39]. Therefore, a combined isotherm was used to predict coupled ion-moisture transport through cement-based materials [32].

\subsection{Pore structure and diffusivity of cement paste}

Cement paste is a porous material with a complex pore structure and solution. Free chloride ions from saline environments dissolve in this pore solution and move through the pore structure. A model developed by Garboczi et al. determines ionic diffusivity of cement pastes as a function of the pore structure. The following equation was derived and fitted to the data [40]:

$\frac{D_{t}}{D_{0}}(\phi)=0.001+0.07 \cdot \phi^{2}+1.8 \cdot H(\phi-0.18) \cdot(\phi-0.18)^{2}$

where, $D_{t}$ is a diffusion coefficient at time $t, D_{0}$ is a diffusion coefficient in free water, $\phi$ is the capillary porosity fraction, and $H$ is the Heaviside function.

Cement particles undergo random growth due to hydration reactions, i.e., the pore structure's influence on chloride diffusivity varies with the degree of hydration of the cement paste. Thus, based on Power's model for ordinary Portland cement pastes, the volume fraction of total $[\phi(\alpha)]$ and water-filled $\left[\phi_{w}(\alpha)\right]$ capillary porosity and unhydrated cement $[\gamma(\alpha)]$ is highly dependent on the degree of hydration $(\alpha)$, and can be estimated as follows [41]:

$\phi(\alpha)=\frac{\rho_{\mathrm{cem}}(w / c)-f_{\mathrm{exp}} \cdot \alpha}{1+\rho_{\mathrm{cem}} \cdot(w / c)}$ 
$\phi_{w}(\alpha)=\frac{\rho_{\mathrm{cem}}(w / c)-\left(f_{\text {exp }}+\rho_{\mathrm{cem}} \cdot C S\right) \alpha}{1+\rho_{\mathrm{cem}} \cdot(w / c)}$

$\gamma(\alpha)=\frac{1-\alpha}{1+\rho_{\mathrm{cem}} \cdot(w / c)}$

where $(w / c)$ is the water-to-cement mass ratio, $\alpha$ is the degree of hydration of the cement at time $t, \rho_{\text {cem }}$ is the specific gravity of cement (here taken to be 3.2), $f_{\exp }$ is the volumetric expansion coefficient for the solid cement hydration products relative to the cement reacted (taken here to be 1.15 [41]), and CS is the chemical shrinkage. Under saturated conditions, the chemical shrinkage is assumed to be compensated for by the imbibition of external curing water $(C S=0)$ [42]. Thus, the total and water-filled porosities are identical.

After verification with experimental data, Bentz recently developed a model to describe the hydration kinetics of Portland cements based on spatial considerations [42]. In this model the hydration rate has a first-order dependence on both the volume fractions of available water-filled porosity and unhydrated cementlike bimolecular-type reactions. In terms of these phase fractions, the hydration rate is expressed as:

$\frac{\partial \alpha}{\partial t}=k \cdot \phi_{w}(\alpha) \cdot \gamma(\alpha)$

where $k$ is a rate constant. Substituting Equations (4) and (5), the following analytical solution was obtained:

$\alpha(t)=\frac{p\{\exp [R(1-p) t]-1\}}{\{\exp [R(1-p) t]-p\}}$

with $p=\rho_{\text {cem }}(w / c) /\left(f_{\exp }+\rho_{\text {cem }} C S\right)$ and $R=k\left(f_{\exp }+\rho_{\text {cem }} C S\right) /$ $\left[1+\rho_{\text {cem }}(w / c)\right]^{2}$. The models presented above were employed herein to simulate the chloride uptake from the cement paste in order to obtain the ionic diffusion coefficient at time $t$.

\section{Chloride transport model in cement paste with the inclusion of CLDH}

This study aimed to simulate the effect of CLDH on the chloride distribution over the cement matrix that initially contained uniform chloride contents. Chloride transport in the cementitious system was modeled by a Fickian diffusion model [43]:

$\frac{\partial C}{\partial t}=\nabla \cdot\left(D_{t} \nabla C\right)-r_{t}$

where, $C$ is the chloride concentration at time $t$, and $r_{t}$ is the adsorption rate at time $t$. Most advanced models-such as the electrochemical chloride removal (ECR) [44] and Nernst-Planck/ Poisson model [33]-include electro-neutrality in the presence of ionic charges, however here it is reasonable to use the Fickian diffusion model to simulate the chloride transport in cement paste influenced by CLDH. Ionic interactions have a minor effect on the chloride diffusion process without externally applied voltage, with the adsorption process being a dominant condition in the ionic transport. Wang et al. [45] investigated the structure and dynamics in the interlayer of ordered $\mathrm{Mg} / \mathrm{Al} \mathrm{Cl}-\mathrm{LDH}\left(\left[\mathrm{Mg}_{3} \mathrm{Al}(\mathrm{OH})_{8}\right] \mathrm{Cl} \cdot 3 \mathrm{H}_{2} \mathrm{O}\right)$ with molecular dynamic simulation and far-infrared spectroscopy (FIR) and observed that interlayer chloride motions are remarkably similar to free chloride motions in aqueous solution due to the similarity of the nearest-neighbor of the chloride in the interlayer and the solution. Therefore, in the simulation reported herein, it is assumed that adsorbed chloride ions are homogeneously distributed over the CLDH particle, reflecting the active movements of chloride ions in the interlayer space.

Integrating Equations (2), (4), (5), and (7) allow for solving Equation (8) using the finite element method (FEM) because of the time variation in the diffusion coefficient and the adsorption rate. To derive the numerical model, the equation is applied to the Galerkin method by using the virtual concentration $(\delta C)$ over the domain $(\Omega)$ :

$(\delta C) \frac{\partial C}{\partial t}=(\delta C) \nabla \cdot\left(D_{t} \nabla C\right)-(\delta C) r_{t}$

By applying the divergence theorem and the explicit scheme, the numerical model is expressed as:

$$
\begin{aligned}
\{C\}^{t+\Delta t}= & \left\{[I]-\frac{D_{t}}{\Delta t}\left[\int_{\Omega}[N]^{T}[N] \mathrm{d} \Omega\right]^{-1}\left[\int_{\Omega}[B]^{T}[B] \mathrm{d} \Omega\right]\right\}\{C\}^{t} \\
& -\left\{\int_{\Omega}[N]^{T} \mathrm{~d} \Omega\right\} r_{t}
\end{aligned}
$$

where, $[N]$ is a shape function, $[B]$ is a derivative of the shape function, and $[I]$ is an identity matrix. The above model is now applied to predict the uptake of chloride ions from cement paste when a CLDH particle is placed on the center of an infinite cement matrix. As shown in Fig. 1, because the concentration gradients in the cement matrix are highest near the cement-particle interface, a variable mesh density is used, whereby the density of the mesh increases in the cement matrix near the interface. This is done to increase accuracy and reduce computational time.

\section{Experimental}

\subsection{Sample preparation}

The Mg/Al LDH (PURAL MG 63 HT, Mg:Al = 2.15:1) used for preparing CLDH was supplied by the SASOL GmbH, Germany, and CLDH was obtained by calcining the precursor LDH in a muffle furnace at $450{ }^{\circ} \mathrm{C}$ for $3 \mathrm{~h}$. The cement paste specimens were made from ASTM Type I Portland cement, the composition of which is

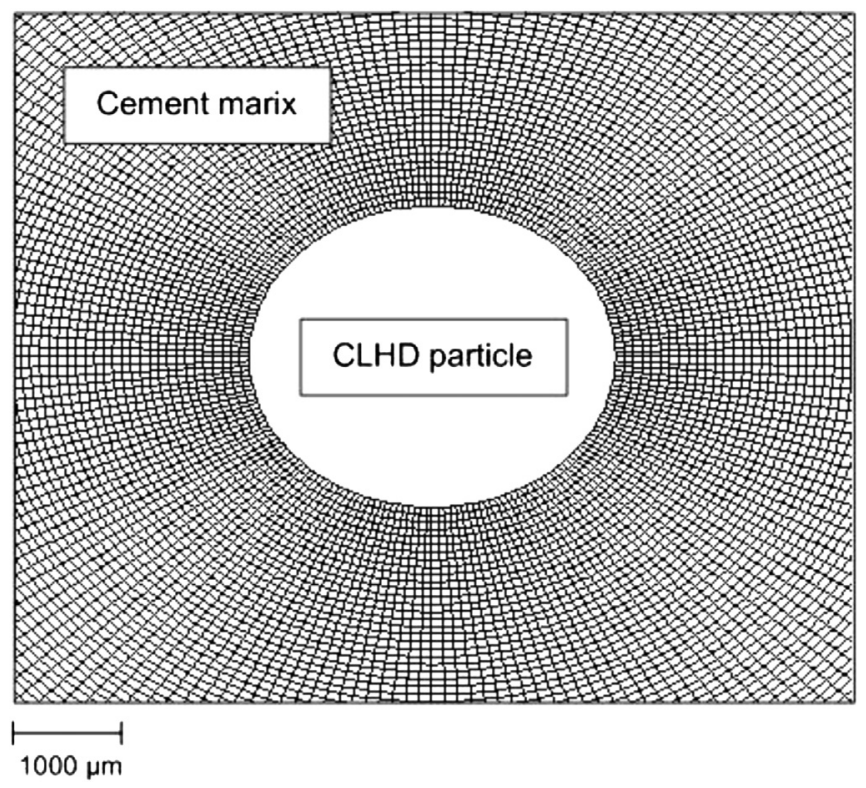

Fig. 1. Mesh generation of cement matrix with inclusion of CLDH. 
listed in Table 1 . The percentage of CLDH used as an admixed inhibitor against chloride attack was $8.5 \%$ by the total mass of the solid pre-calculated to absorb approximately $2 \%$ of chloride content, which reflected the boundary content of the concrete specimen exposed to seawater for 2 years (see Ref. [46]). To assess the effect of CLDH, control specimens of cement pastes that did not contain CLDH were also prepared for every mix design. Compressive strength results were obtained using a Baldwin Universal testing machine. Chloride levels were managed by using $0.3,0.6$, $0.8,1$, and $3 \mathrm{M} \mathrm{NaCl}$ solutions as mix water, obtaining homogeneous chloride contents for all specimens (see Refs. [25,47,48]). A solution-to-solid ratio of 0.4 was considered to be the benchmark. For each mix, two cylindrical specimens ( $\varnothing 2.5 \mathrm{~cm} \times 2.5 \mathrm{~cm}$ )-one the control and the second the CLDH specimen-were cast and steam-cured at $20{ }^{\circ} \mathrm{C}$ for all test ages. Therefore, the numbers of specimens were 20 and 24, respectively, for the equilibrium and kinetic studies.

\subsection{Equilibrium}

The equilibrium isotherms were carried out by using different chloride levels. All specimens were cured over 28 days, which is acknowledged as not being the exact time required to reach perfect equilibrium; however, this assumption was made because a 28-day curing period has been commonly used as the standard to reach equilibrium in hydration kinetics [49]. The final concentration of free chloride in the cement paste was determined by following ASTM C 1218 [50]; therefore, pulverized samples were crushed from the cement paste by using the dry-grinding technique and measured for water-soluble chloride using a chloride meter for concrete provided by DAE YOUNG WIRE Co., LTD. The duration of extraction was $24 \mathrm{~h}$, and, when we started the measurement, the display of the chloride meter incremented and stopped at the value of the chloride concentration that we used. The chloride loading for CLDH specimen was calculated from the following equation:

$q_{e}=\frac{\left(C_{0}-C_{e}\right) M}{m} \times \frac{1000}{100}\left(\frac{\mathrm{mg}}{\% \text { cement }}\right)$

where $q_{e}$ is the adsorption loading of CLDH at equilibrium $\left(\mathrm{mg} \mathrm{g}^{-1}\right)$, $m$ is the mass of CLDH in each specimen $(\mathrm{g}), M$ is the total mass of one specimen ( $\mathrm{g}$ ), and $C_{0}$ and $C_{e}$ (\% cement) are the chloride concentrations of the control and cement-CLDH specimens, respectively. Since the measured unit of chloride contents in the cement paste is percentage by mass of cement (\% cement), the total mass of the specimens $(M)$ was used instead of the volume of the solution, which is the method commonly used in other equilibrium studies.

\subsection{Kinetics}

The kinetic study used $0.1,0.3$, and $0.6 \mathrm{M} \mathrm{NaCl}$ solutions as mix water. Using an identical procedure as that outlined for the equilibrium study, the chloride contents were measured at $1,3,7$, and 28 days. Control specimens were also prepared and cured under identical conditions. The measured specimens were subjected to additional experiments using XRD, X-ray fluorescence (XRF), and SEM. Chloride uptake by CLDH was calculated using the following equation:

Table 1

Chemical composition of cement (mass fraction, \%).

\begin{tabular}{lllllllll}
\hline $\mathrm{SiO}_{2}$ & $\mathrm{Al}_{2} \mathrm{O}_{3}$ & $\mathrm{Fe}_{2} \mathrm{O}_{3}$ & $\mathrm{CaO}$ & $\mathrm{MgO}$ & $\mathrm{K}_{2} \mathrm{O}$ & $\mathrm{Na}_{2} \mathrm{O}$ & $\mathrm{SO}_{3}$ & LOI \\
\hline 20.2 & 5.2 & 5.5 & 62.2 & 1.0 & 0.7 & 0.2 & 4.1 & 1.5 \\
\hline
\end{tabular}

$q_{t}=\frac{\left(C_{0}-C_{t}\right) M}{m} \times \frac{1000}{100}\left(\frac{\mathrm{mg}}{\% \text { cement }}\right)$

where $q_{t}$ is the adsorption loading of CLDH at time $t\left(\mathrm{mg} \mathrm{g}^{-1}\right), m$ is the mass of CLDH in each specimen $(\mathrm{g}), M$ is the total mass of one specimen $\left(\mathrm{g}\right.$ ), and $C_{0}$ and $C_{t}$ (\% cement) are the chloride concentrations of the control and experimental specimens at time $t$ (days), respectively.

CLDH (0.1 g) were dispersed in $20 \mathrm{~mL}$ of chloride solutions and stirred in air for 6 days at room temperature in sealed tubes. Five milliliters aliquots were extracted at selected time intervals and filtered. The chloride concentrations in the solution were measured using a selective electrode for chloride ions. The chloride uptake by the CLDH was calculated from the following equation:

$q_{t}=\frac{\left(C_{0}^{a}-C_{t}^{a}\right) V}{m}$

where $V$ is the volume of solution (L), and $C_{0}^{a}\left(\mathrm{mg} \mathrm{L}^{-1}\right)$ and $C_{t}^{a}\left(\mathrm{mg} \mathrm{L}^{-1}\right)$ are the initial concentration of chloride and that at time $t$, respectively.

\subsection{Measurement of hydration rate constant and compressive strength}

The LOI non-evaporable water content measurement was performed according to the procedure described in Ref. [51]. The nonevaporable water content of the 7-day specimen was obtained by measuring the relative mass loss between 105 and $1000{ }^{\circ} \mathrm{C}$, and then correcting for the LOI of the dry cement powder. A value of $0.25 \mathrm{~g} \mathrm{H}_{2} \mathrm{O} \mathrm{g}^{-1}$ cement-the non-evaporable water content for a fully hydrated sample-was calculated based on the Bogue equations and the chemical composition of the cement, as shown in Table 1 . The degree of hydration $(\alpha=0.59)$ was then estimated as the ratio of the measured non-evaporable water content to the amount for a fully hydrated specimen. The time, $t=7$ days, and the degree of hydration were substituted into Equation (7) to obtain the hydration rate constant $\left(k=0.03 \mathrm{~h}^{-1}\right)$, which was used in further simulations conducted in the present study.

\subsection{Techniques}

The XRD patterns of the samples were obtained using a PANalytical X'Pert Pro diffractometer with a $\mathrm{Cu} \mathrm{K} \alpha(\lambda=1.54 \AA)$ incident radiation. The data were collected from 5 to $70^{\circ}$. The composition maps on the cement paste and admixed CLDH of the 7-day specimens were obtained using Orbis Micro-XRF provided by EDAX. To reduce the possibility of significantly misrepresenting the chloride distribution on the specimen, a relatively flat area of the split specimen was measured; no additional treatment on specimen, such as polishing, was performed. To study the morphological features of the powdered CLDH and reformed LDH included in the cement paste, SEM was conducted using a CAMECA SX 100 and gold-coated specimens.

\section{Results and discussion}

\subsection{Equilibrium isotherm}

Equilibrium isotherms, which are critical in optimizing the use of adsorbents, were measured to study the chloride adsorption by CLDH in a cement-based system. The correlation between equilibrium data and isotherms led to developing a better model that represents well the quantity and operation of adsorption system. In the present study, the quantity of the chloride removals by CLDH in 
cement paste $\left(q_{e}\right)$ were scattered against the chloride concentration equilibrated in the control specimen $\left(C_{e}\right)$ [see Fig. 2(a)]. Two general-purpose equilibrium models were considered to fit the experimental data: (a) Langmuir's [52] model, shown in Equation (14), and (b) Freundlich's [53] model, shown in Equation (15).

$q_{e}=\frac{Q b C_{e}}{1+b C_{e}}$

$q_{e}=K_{F} C_{e}^{1 / n}$

where, $Q$ and $b$ are the Langmuir constants, $K_{F}$ and $n$ are the Freundlich constants, $C_{e}$ is the chloride concentration equilibrated in the cement paste (\% chloride by weight of cement), and $q_{e}$ is the adsorption loading at equilibrium $\left(\mathrm{mg} \mathrm{g}^{-1}\right)$.

Fig. 2(a) shows that the Langmuir isotherm fits the experimental data more satisfactorily than the Freundlich isotherm does, suggesting that the adsorption process takes place at specific homogeneous sites within LDH as assumed by the Langmuir equation. The best-fit Langmuir parameters are $Q=153 \mathrm{mg} \mathrm{g}^{-1}$ and $b=0.418 \%$ cement $^{-1}$. The evaluated chloride uptake in the cement matrix $\left(153 \mathrm{mg} \mathrm{g}^{-1}\right)$ is much less than the stoichiometric calculation $\left(257 \mathrm{mg} \mathrm{g}^{-1}\right)$, implying that other anions in the cement paste pore solution might be adsorbed into CLDH as well by competing with chloride ions. Molecular Dynamics (MD) has recently been applied to better understand ionic and moisture adsorption by cementitious phases [54-56]. The chloride-binding capacity observed in MD simulations decreases in the sequence Friedel's salt $>$ portlandite $>$ ettringite $>$ tobermorite [54]. The theoretical amount of bound chloride by Friedel's salt ( $\mathrm{Cl}-\mathrm{AFm}$ phase), which has the highest binding capacity among cementitious phases, is $2.0 \mathrm{~mol} \mathrm{~mol}^{-1}\left(121 \mathrm{mg} \mathrm{g}^{-1}\right)$. Recently, Hirao et al. reported $1.8 \mathrm{~mol} \mathrm{~mol}^{-1}$ (or $109 \mathrm{mg} \mathrm{g}^{-1}$ ) of chloride uptake by the AFm phase at $5 \mathrm{~mol} \mathrm{~L}^{-1} \mathrm{NaCl}$ solution [30]. Since this experiment was performed in a dilute solution not a cement matrix, the effective binding capacity of AFm phases in the cement matrix can be less because of the presence of other competitive anions in the pore solutions of the cement matrices. Therefore, the measured and theoretical binding capacities ( $153 \mathrm{mg} \mathrm{g}^{-1}$ and $257 \mathrm{mg} \mathrm{g}^{-1}$ ) of CLDH in the cement matrix are comparable to those of the AFm phase.

\subsection{Adsorption kinetics and compressive strength}

To determine the appropriate mechanism, kinetic models were compared with the experimental data. The key features of the kinetic models used in the present study can be summarized as follows:

\subsubsection{Pseudo first-order kinetics model}

The pseudo first-order kinetics model suggested by Lagergren [57] is given by the following linear equation:

$\ln \left(q_{e}-q_{t}\right)=\ln q_{e}-k_{1} t$

where $k_{1}$ is the rate constant of adsorption (days ${ }^{-1}$ ), and $q_{e}$ and $q_{t}$ are the amount of chloride adsorbed at equilibrium and at time $t$

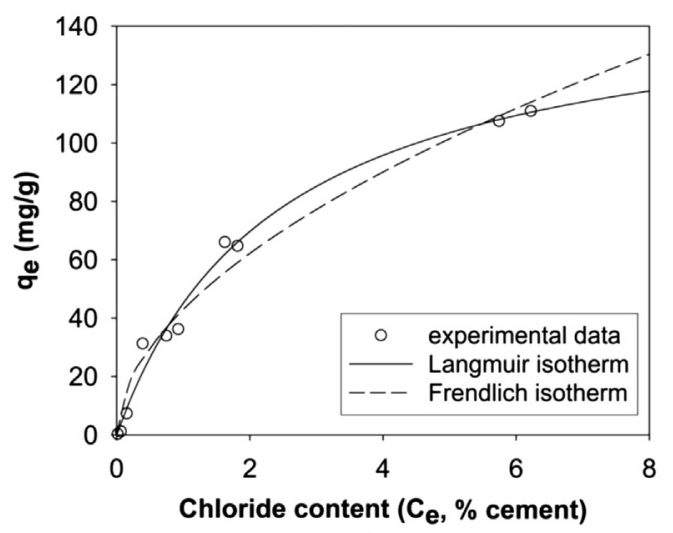

(a)

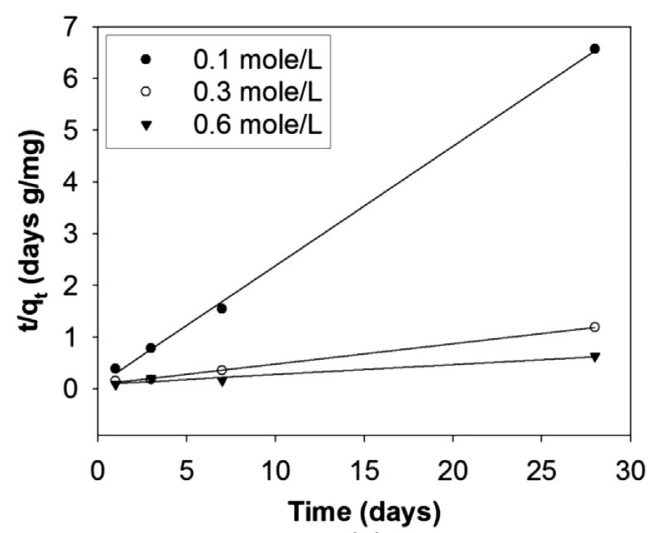

(c)

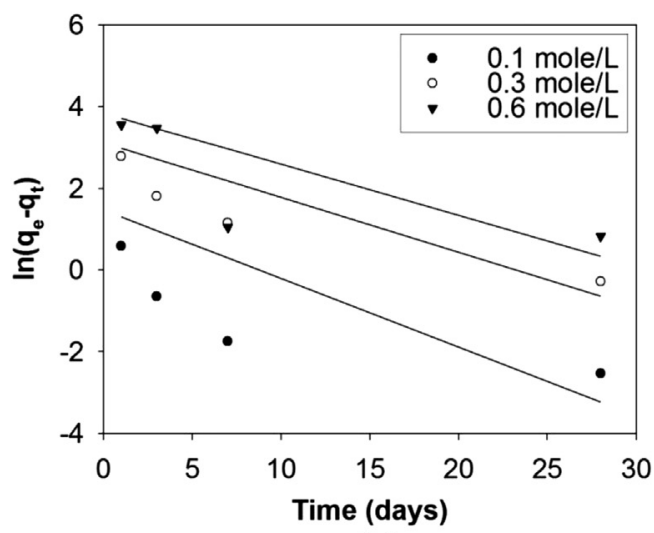

(b)

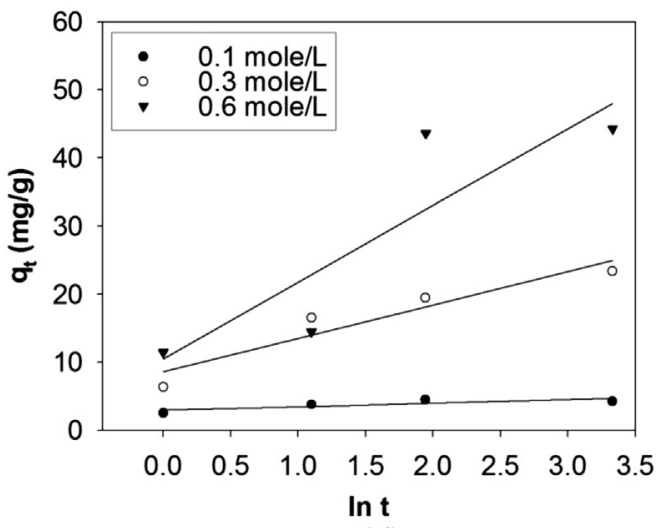

(d)

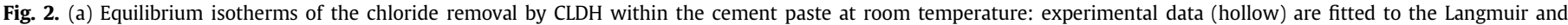

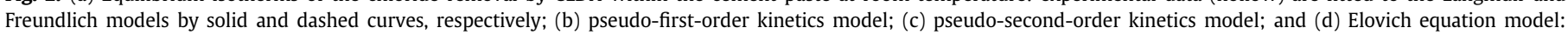
experimental data obtained at 1, 3, 7, and 28 days were measured and fitted to the kinetics models in (b), (c) and (d). 
(days), respectively. Plotting $\ln \left(q_{e}-q_{t}\right)$ versus $t$ results in a straight line, and its slope is the rate constant, $k_{1}$. Fig. 2(b) shows the fitted model compared to the experimental data.

\subsubsection{Pseudo second-order kinetics model}

The pseudo second-order model $[58,59]$ also illustrates the kinetics of sorption in the solid/liquid systems. The linearly expressed equation is as follows:

$\frac{t}{q_{t}}=\frac{1}{k_{2} q_{e}^{2}}+\frac{1}{q_{e}} t$

where, $k_{2}$ ( $\mathrm{g} \mathrm{mg}^{-1}$ days) is the rate constant of the pseudo secondorder kinetics. The rate constant can be calculated from the straight line fitted to the experimental data in Fig. 2(c).

\subsubsection{Elovich equation}

The adsorption data may also be analyzed using the Elovich equation $[60,61]$, whose linear form is:

$q_{t}=\frac{1}{\beta} \ln (\alpha \beta)+\frac{1}{\beta} \ln t$

where, $\alpha$ is the initial sorption rate constant ( $\mathrm{mg} \mathrm{g}^{-1}$ days), and $\beta$ is the desorption constant $\left(\mathrm{g} \mathrm{mg}^{-1}\right)$. The constants can be obtained from the slope and intercept of the plot of $q_{t}$ versus $\ln (\mathrm{t})$, as shown in Fig. 2(d).

Fig. 2(b), (c), and (d) presents the results of fitting the experimental data to the pseudo first-order, pseudo second-order, and Elovich models. The figure demonstrates that the pseudo secondorder model is the most suitable in describing the absorption kinetics of chloride by CLDH admixed into the cement paste. Table 2 lists all of fitted parameters for the pseudo second-order model. According to the assumptions of the pseudo second-order kinetics model, the chemical interaction between the chloride ions and CLDH is responsible for the binding capacity of the CLDH. The rate constant, $k_{2}$, is shown in Table 2 . The compressive strength evolution of the samples is presented in Fig. 3. CLDH slightly reduced the compressive strengths of the cement paste during the early ages, but the 28-day strengths are almost similar. Duan et al. reported the long-term compressive strength of sulfoaluminate cement concrete mixtures containing LDHs and CLDHs [62]. At 84 days, LDHs showed improved compressive strength of approximately $5 \%$ and CLDHs showed reduced compressive strength of 5\% compared to the reference sample. The long-term effects of CLDHs or LDHs on compressive strength of cement-based materials, therefore, do not appear to be significant.

\subsection{Adsorption process}

The 7-day specimen prepared with $0.6 \mathrm{M} \mathrm{NaCl}$ solution and CLDH was subjected to additional testing to explore the chemical distributions in the middle of the adsorption process before an equilibrium state is reached. The composition maps for $\mathrm{Mg}, \mathrm{Al}, \mathrm{Si}$, $\mathrm{Cl}, \mathrm{S}, \mathrm{K}$, and Fe elements were determined by XRF in terms of oxide weight percent over the selected region of the specimen. Based on $\mathrm{Mg}, \mathrm{Al}$, and Si maps shown in Fig. 4, the $\mathrm{Mg} / \mathrm{Al}$ ratio and the weight

Table 2

Regression coefficients $\left(R^{2}\right)$ and kinetic parameters for the pseudo second-order kinetics model.

\begin{tabular}{llcl}
\hline$\left[\mathrm{Cl}^{-}\right]$of mix water $\left(\mathrm{mol} \mathrm{L}^{-1}\right)$ & $R^{2}$ & $q_{e}\left(\mathrm{mg} \mathrm{g}^{-1}\right)$ & $k_{2}\left(\mathrm{~g} \mathrm{mg}^{-1}\right.$ days $)$ \\
\hline 0.1 & 0.9988 & 4.3309 & 0.7355 \\
0.3 & 0.9979 & 25.3796 & 0.0174 \\
0.6 & 0.9559 & 51.6840 & 0.0045 \\
\hline
\end{tabular}

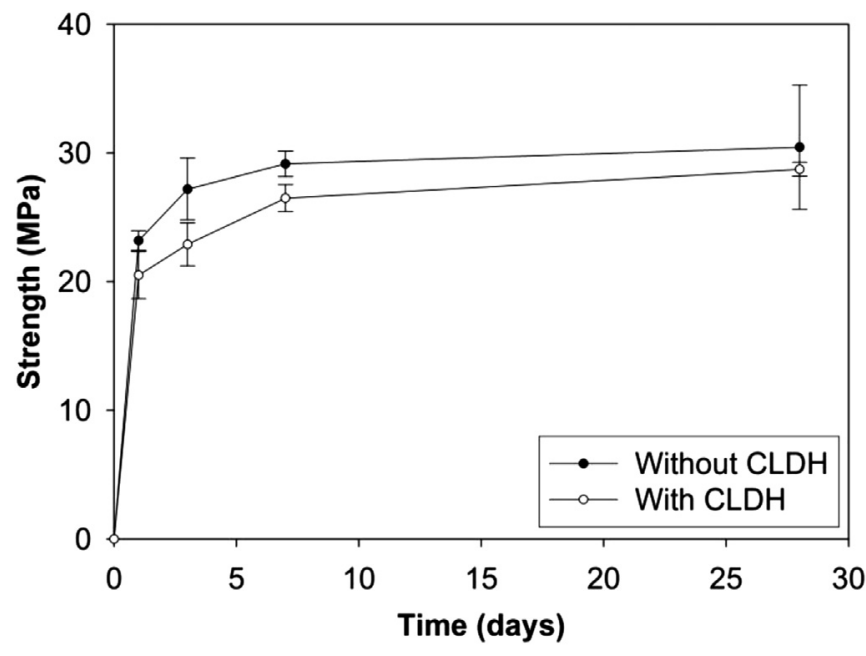

Fig. 3. Strength development of the cement paste with CLDH and without CLDH.

percent of $\mathrm{SiO}_{2}$ confirm that the particle is $\mathrm{CLDH}$, and that the outer region surrounding the particle is cement paste (see Fig. 4). The $\mathrm{Cl}$, $\mathrm{S}, \mathrm{K}$, and Fe map (Fig. 4) shows that CLDH is remarkably effective in adsorbing anions without adsorbing cations from the cement paste pore solution. The $\mathrm{Cl}$ map reveals remarkable differences in the chlorine content between CLDH and the cement matrix, indicating that CLDH is an effective absorbent that prevents chloride-induced deterioration in reinforced concrete. Although the weight percent of $\mathrm{SO}_{3}$, which is the unit presented by micro-XRF, is higher than that of $\mathrm{Cl}_{2} \mathrm{O}$ absorbed into the $\mathrm{CLDH}$ particle (see Fig. 4), the molar percent of $\mathrm{S}$ and $\mathrm{Cl}$ is similar as the unit is converted from oxide weight to molar percent. Because gypsum-one of the main ingredients of cement-is the source of sulfate, the high sulfate content of the cement matrix means that the sulfate competes with chloride to be adsorbed into CLDH.

A simulation of the process of chloride adsorption by CLDH in a cementitious environment was conducted and is shown in Fig. 5(a), (b), and (c). Fig. 5(d) shows the upper surface (three-dimensional) plot of the chlorine distribution obtained from the XRF map over the area of the microscopic image on the bottom plane. The simulated chloride distribution of 7-day specimens in Fig. 5(c) is in good agreement with the distribution measured with XRF in Fig. 5(c). Interestingly, the chloride contents are rapidly removed in the cement-matrix regions adjacent to the CLDH particle, and subsequently, the regions influenced by CLDH expand to the outer regions over time.

Because of the tortuous pore structure of the cement matrix, it is difficult for chloride ions to freely move in cement matrix-unlike in the aqueous solution-reflecting the low ionic diffusivity of cement-based materials. For this reason, it takes a long time for chloride ions to diffuse into the region influenced by CLDH particles. However, the rate change does not indicate a decrease or increase in the total binding capacity of CLDHs because the equilibrium constant of pore solutions is not affected by pore structure. With low permeability, both chloride uptake by CLDHs and chloride diffusion are slow. Therefore, the pore structures do not significantly affect the total content of bound chloride by CLDHs. The limited ionic movement causes the region of the cement matrix adjacent to the CLDH particle to have a lower chloride content than its bulk region, slowing down the adsorption rate. To thermodynamically compensate for the deficient chloride contents of adjacent regions, over the long-term chloride ions in outer regions away from CLDH are slowly transported to the regions adjacent to CLDH, thereby reducing the overall chloride contents of the cement matrix. 

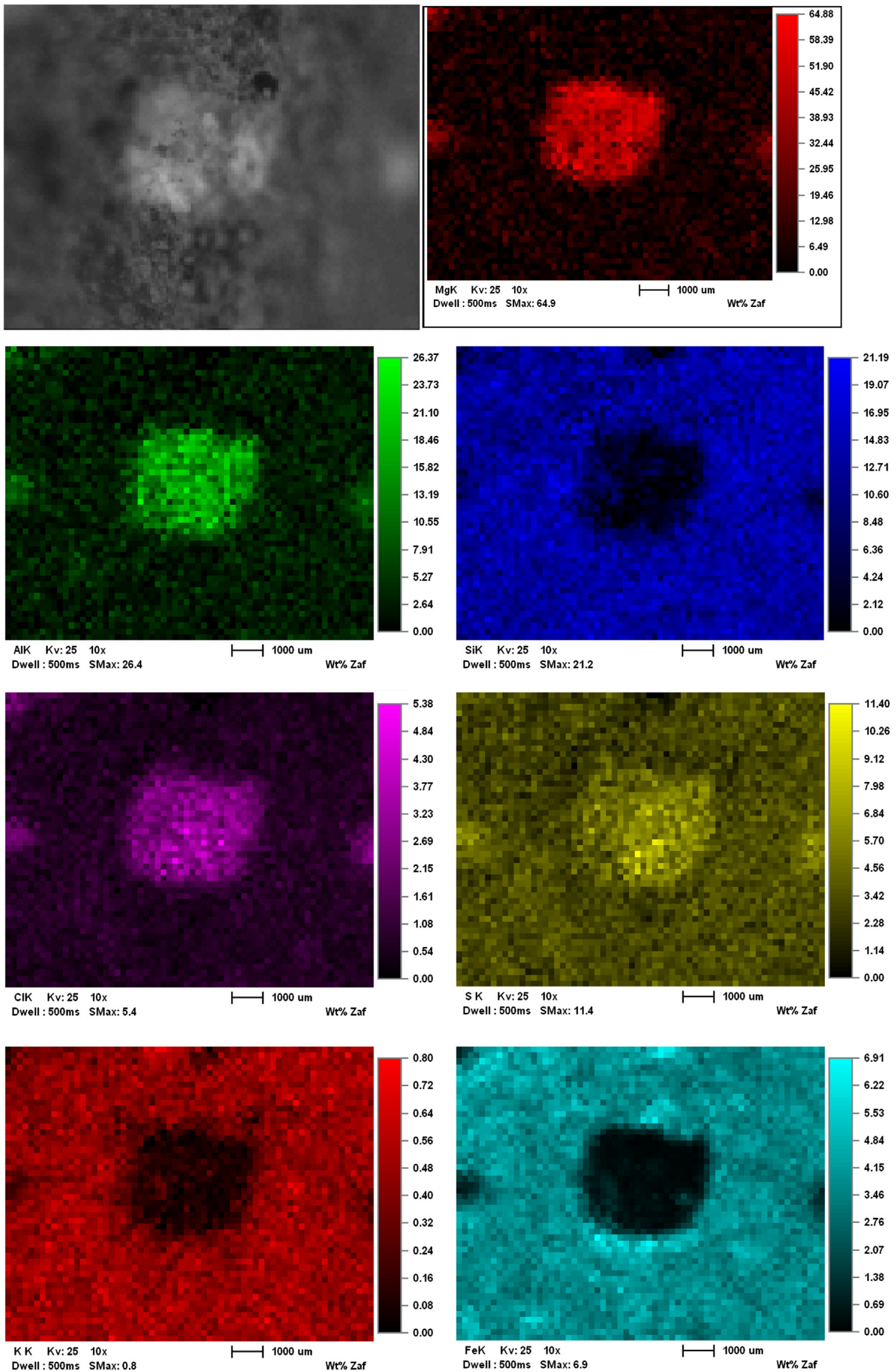

Fig. 4. Microscopic image and $\mathrm{X}$-ray fluorescence maps showing distributions of elements $(\mathrm{Mg}, \mathrm{Al}, \mathrm{Si}, \mathrm{Cl}, \mathrm{S}, \mathrm{K}$, and $\mathrm{Fe})$ by oxide weight percent 


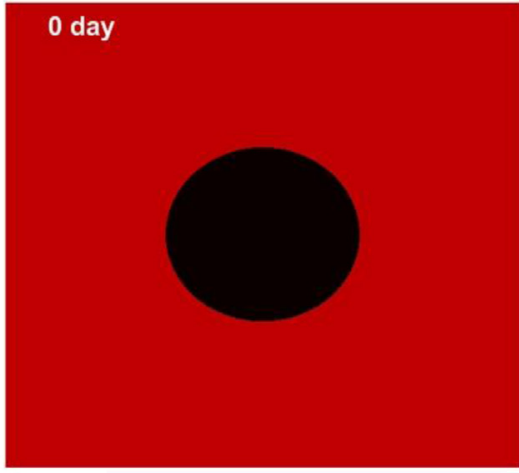

(a)

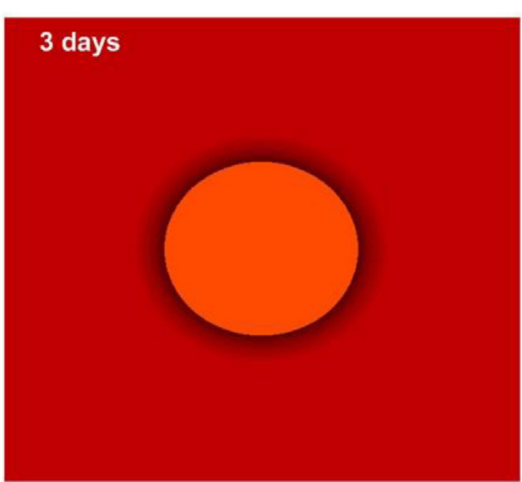

$\stackrel{\vdash}{1000 \mu \mathrm{m}}$

(c)
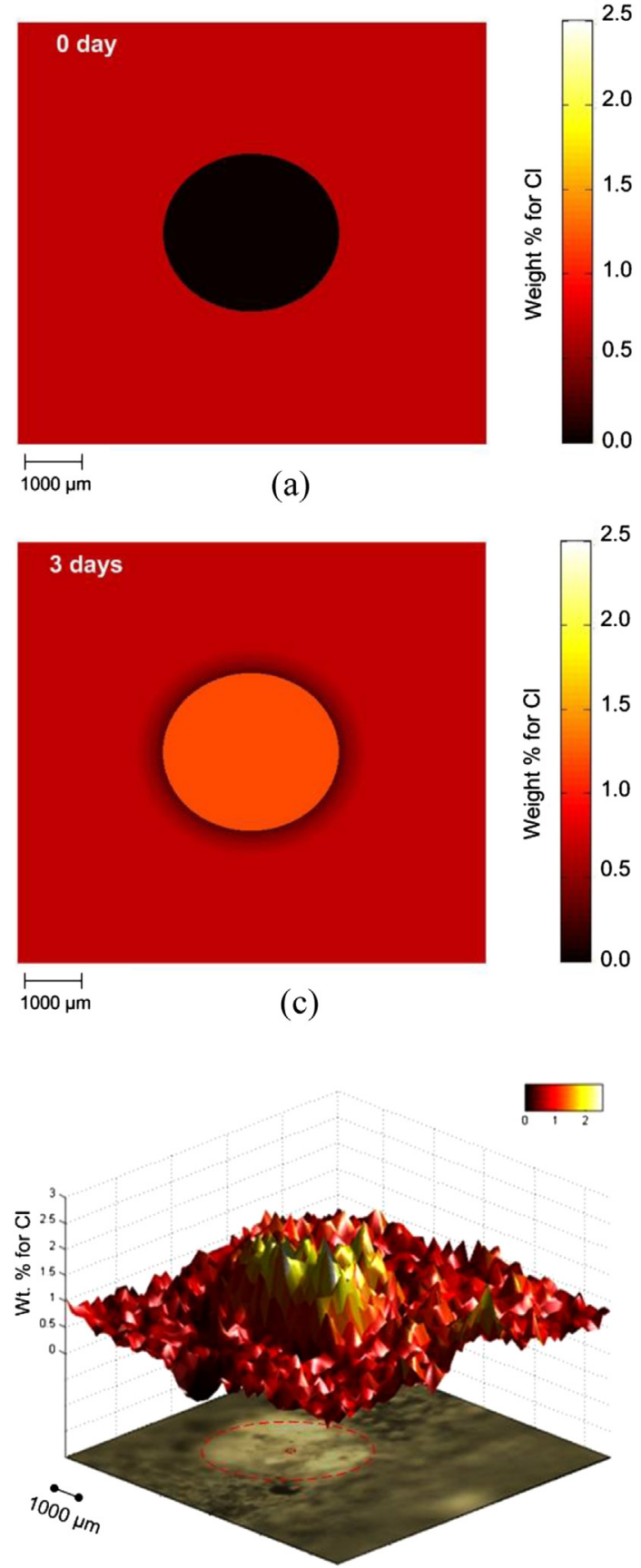

(e)
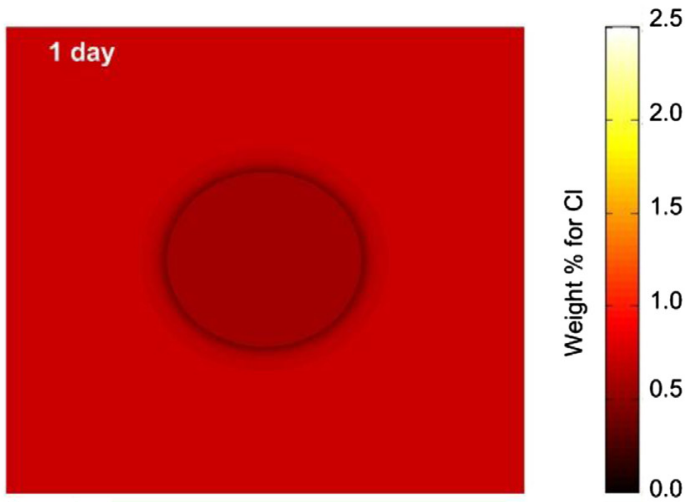

$1000 \mu \mathrm{m}$

(b)
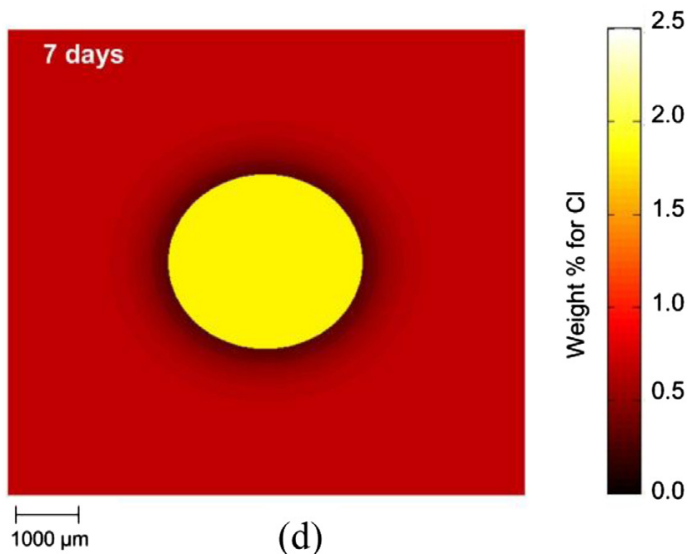

(d)

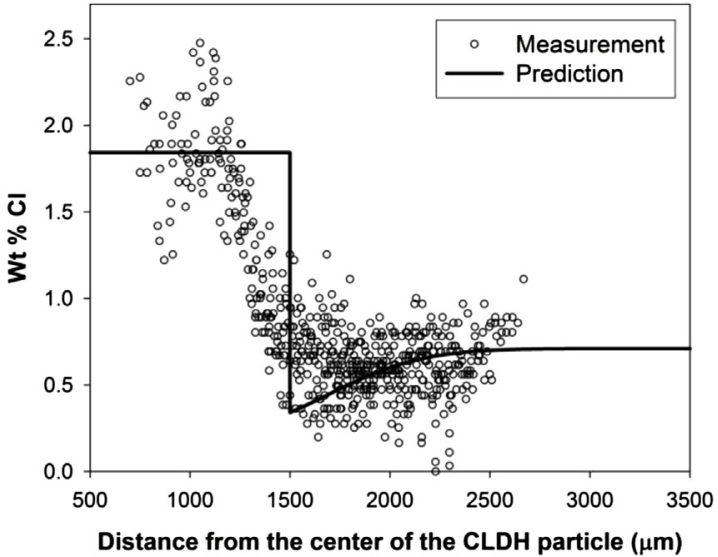

(f)

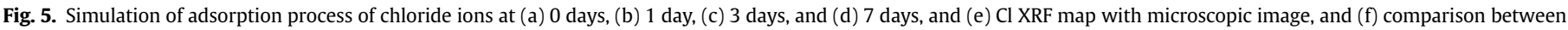
the measurements obtained from (e) and the prediction obtained from (d) in terms of the distance from the center of the CLDH particle.

In aqueous solution, temperature is an important parameter in the adsorption process. On the other hand, in the hydrated cement matrix, a highly dominant parameter in the adsorption process is its pore structure. Within the temperature range at which its pore structure is intact, ions presented in its pore solution still have to go through the pathway of the pore structure even though they are more active at a higher temperature. Therefore, if the saturated condition is kept in the hydrated cement matrix, the effect of temperature on the adsorption rate in the hydrated cement matrix might be less than in the aqueous solution. In contrast, relative humidity $(\mathrm{RH})$ controls the amount of liquid and gas phases in the pore structure. Lower RH means reduction in the proportion of the liquid phase, and thus the pathway through which ions move becomes more tortuous because ions are able to move only through the liquid phase of the pore structure. Therefore, RH will affect the adsorption rate in the cement paste.

\subsection{Comparison of adsorption process in cement paste and aqueous solution}

Following the experimental method mentioned in Section 4.3, we also studied the kinetics of chloride uptake by CLDH in aqueous 
solutions to compare it to that in cement paste. Fig. 6 shows the comparison of adsorption kinetics in cement paste and aqueous solution. The adsorption rate in the cement paste is much slower than that in aqueous solution at the early stages of adsorption. While the adsorption in solution reaches a plateau quickly, CLDH continues to adsorb in the cement matrix. We attribute the slower kinetics in the cement matrix to the rate-limiting diffusion process. Thus we expect the adsorption rate to vary with the different pore structure of the cementitious materials. The reconstructed LDHs have a similar structure in both the cement paste and aqueous solution, suggesting that the cementitious environment has no effect on reforming the layer structure of the $\mathrm{LDH}$.

\subsection{Structure and morphology}

The XRD patterns of two cement pastes specimens-the control and CLDH-cement paste specimen-are shown in Fig. 7(a) and (b). When CLDH interacts with chloride ions in aqueous solution, the layered structure reconstructs [like the latter feature shown in Fig. 8 and its XRD pattern is shown in Fig. 7(c)]. The new peaks shown in Fig. 7(b) appeared in identical positions of the $\mathrm{Mg} / \mathrm{Al}-\mathrm{Cl}$ LDH in Fig. 7(c), indicating that the CLDH admixed in the cement matrix also reconfigured itself with anions in the layered structure. Fig. 8 shows the schematic illustration of the CLDH structure reconstructed with intercalated anions. After LDH is calcined at $500{ }^{\circ} \mathrm{C}$, its layered structure disappears (identically to that shown Fig. 8); its XRD pattern as raw CLDH is shown in Fig. 7(d). The XRD patterns in Fig. 7 are evidence that the cementitious environment does not have any effect on the reformed structure of CLDH.

The representative morphologies of the raw CLDH and the reformed LDH by adsorbing anions in the cementitious environment are shown in Fig. 9. The raw CLDH in Fig. 9(a) has plate-like particles with sharp edges, in addition to some particles that are settled with well-defined hexagonal shape but no defined orientation. After adsorbing anions from the cement matrix, the materials appear to be constituted of well-defined lamellar shapes stacked on top of each other. In addition, it can be seen from Fig. 9(b) that the edges of the reformed LDH in the cement paste are more irregular than those of the raw CLDH. In addition, their crystalline sizes have increased compared to the smaller particles of the raw CLDH. Clearly the growth of the crystal was not homogeneous for all particles.

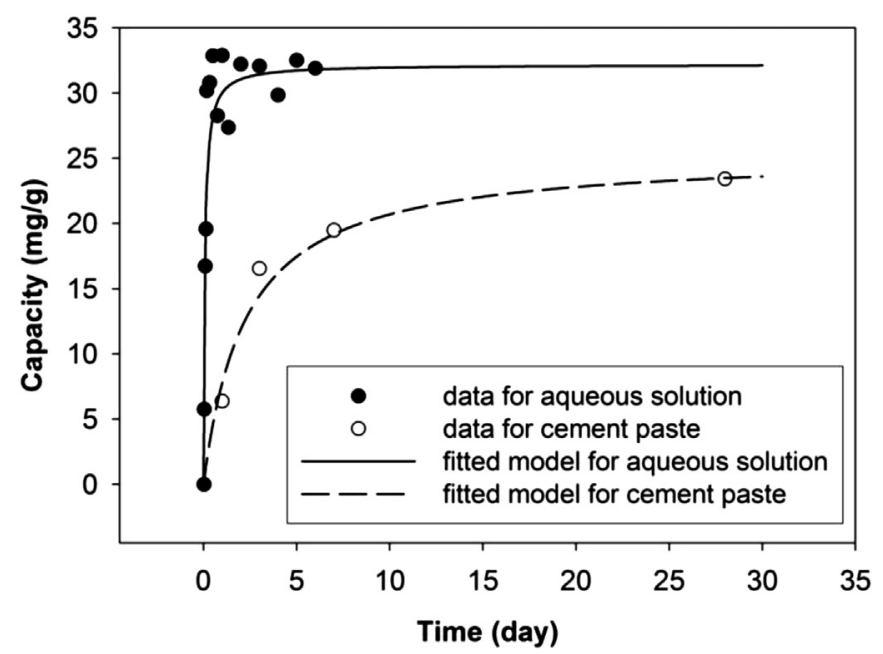

Fig. 6. The kinetics of uptake of chloride by CLDH in the cement paste and aqueous solution.

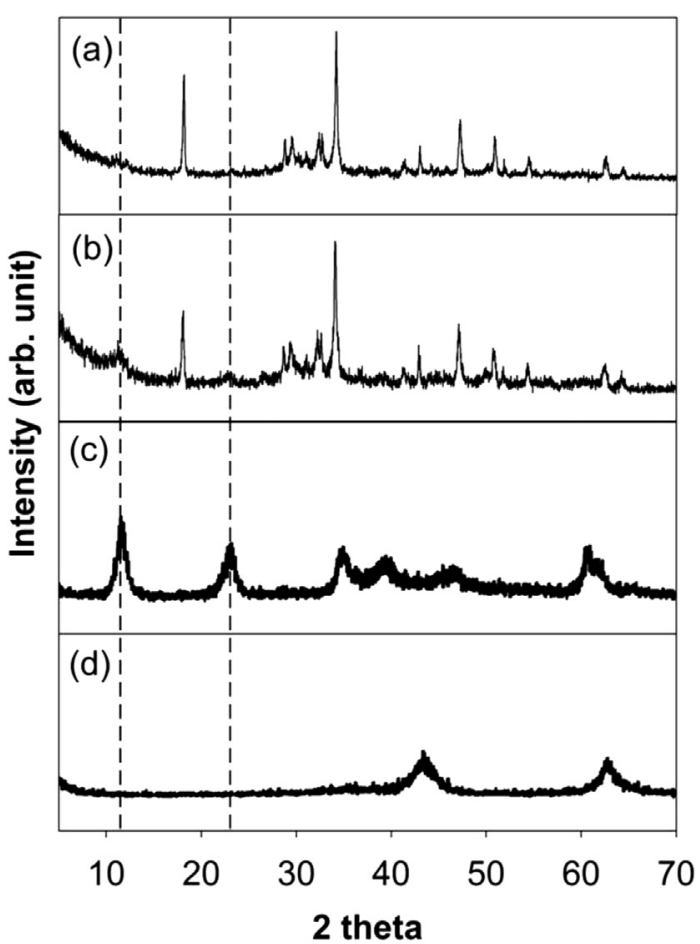

Fig. 7. Powder XRD patterns: (a) cement paste without CLDH; (b) cement paste with $\mathrm{CLDH}$; (c) $\mathrm{Mg} / \mathrm{Al}-\mathrm{Cl} \mathrm{LDH}$; and (d) raw CLDH.

\subsection{Application of CLDH to the cement and concrete industry}

Sustainable development of concrete infrastructure is a major challenge in today's construction industry; the use of admixed or supplementary materials is an integral component in addressing this issue. The existence of LDH-like phases in cement matrix, such as AFm phases, has been thought to improve the corrosion resistance of the reinforced concrete structure by preventing chlorideinduced deterioration. The beneficial effects of AFm phases on adsorbing chloride from hardened cement support the idea of using CLDH in concrete as an effective chloride absorbent. Both surfaceapplied and admixed methods can be employed for the use of CLDH. In fact, Tatematsu and Sasaki [9] plastered the corrosioninhibiting paste admixed with hydrocalmite-one of LDHs-on the surfaces of $\sim 1-\mathrm{mm}$-thick reinforced steel bars. Thus CLDH can be also applied in same fashion with hydrocalmite. Because limestone undergoes heat treatment of over $500{ }^{\circ} \mathrm{C}$ in the manufacturing process of Portland cement, LDH can be transformed to CLDH and admixed to cement powder if LDH goes through the heat treatment simultaneously with the limestone. There are a variety of ways to utilize CLDH in the construction industry. This study has demonstrated the effects of CLDH on chloride uptake in a cement-based environment, suggesting that CLDH has potential as a chloride absorbent in concrete.

\section{Conclusion}

An experiment study of the efficacy of calcined layered double hydroxide (CLDH) in reducing the chloride content in the cement paste was conducted. The experimental data was fitted using both Langmuir and Freundlich equations to determine the equilibrium isotherm. An evaluation of both models demonstrated that the Langmuir model fit the experimental results to a satisfactory degree, indicating that all adsorption sites are equivalent. The kinetic data were successfully fitted using the pseudo second-order kinetic 

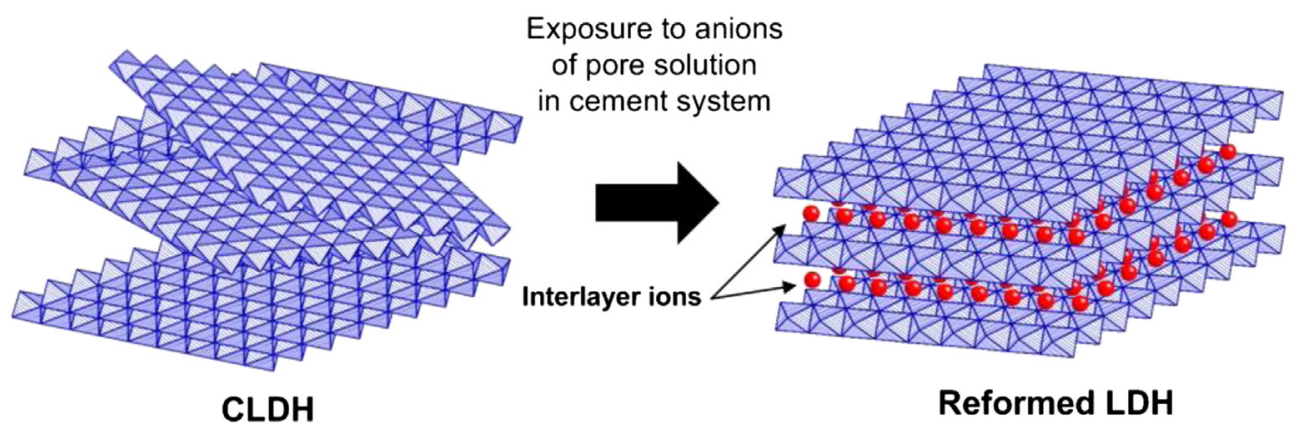

Fig. 8. Schematic illustration of reforming layered structure of CLDH by adsorbing anions.

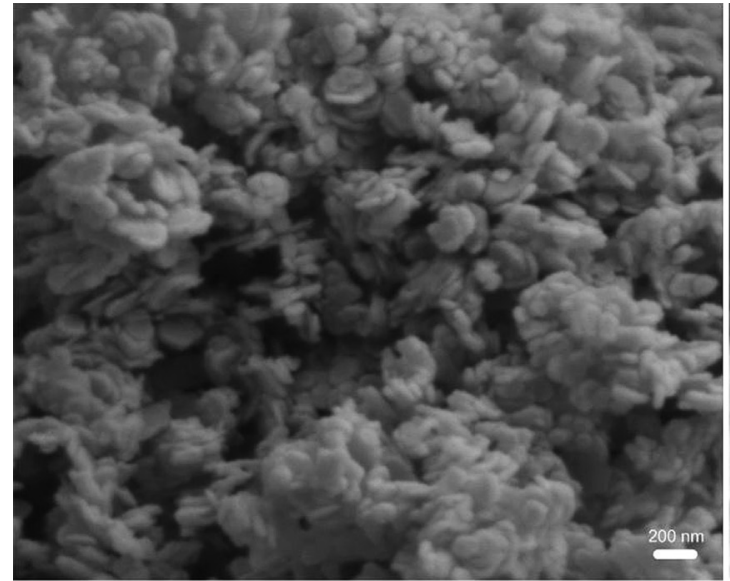

(a)

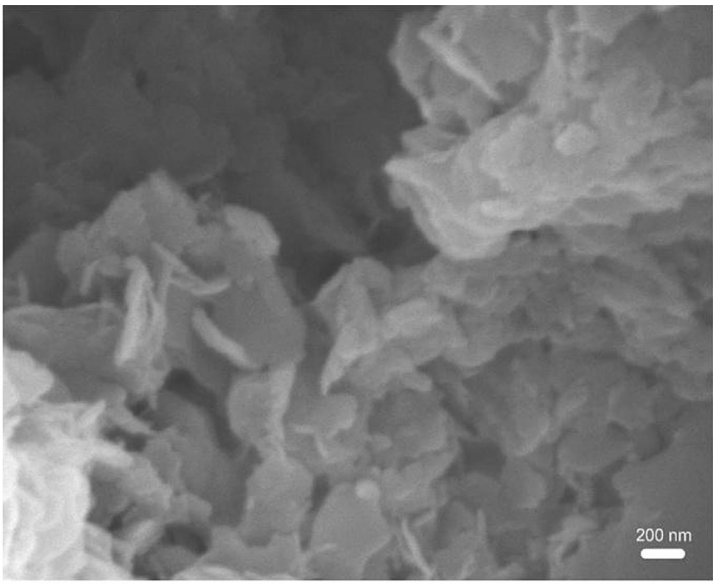

(b)

Fig. 9. SEM micrographs: (a) raw CLDH; and (b) reformed LDH in the cement paste.

model. Based on the kinetic study and the Fickian diffusion model, the adsorption process in the cement paste was simulated and compared with a $\mathrm{Cl}$ map determined using XRF. The simulations show that the chloride transport in a cement matrix governs the adsorption rate, whereas chemisorption is the dominant process for aqueous solutions. In addition, according to the XRD analysis and SEM images, the CLDH admixed in the cement paste not only reconstructed the layered structure with anions, but grew in an irregular morphology. Based on the results of this study, the use of CLHD in cementitious materials has extraordinary potential in preventing the chloride-induced deterioration of the reinforced concrete. Given the robust results presented herein, future work on the application of CLDH in cementitious materials will proceed rapidly, providing remarkable improvement in the durability of RC structures exposed to saline environments. This study will contribute fundamental information to these further research.

\section{Acknowledgments}

This publication was based on work supported in part by Award No. KUS-11-004021 and No. KUS-C1-018-02, made by King Abdullah University of Science and Technology (KAUST). We acknowledge Sasol Company for a sample of Pural MG 63 HT.

\section{References}

[1] C. Alonso, C. Andrade, M. Castellote, P. Castro, Chloride threshold values to depassivate reinforcing bars embedded in a standardized OPC mortar, Cem. Concr. Res. 30 (2000) 1047-1055.
[2] M. Saremi, E. Mahallati, A study on chloride-induced depassivation of mild steel in simulated concrete pore solution, Cem. Concr. Res. 32 (2002) 1915-1921.

[3] P.K. Mehta, P.J.M. Monteiro, Concrete: Microstructure, Properties, and Materials, McGraw-Hill, New Jersey, 2006.

[4] T.A. Söylev, M.G. Richardson, Corrosion inhibitors for steel in concrete: stateof-the-art report, Constr. Build. Mater. 22 (2008) 609-622.

[5] C. Andrade, C. Alonso, M. Acha, B. Malric, Preliminary testing of $\mathrm{Na}_{2} \mathrm{PO}_{3} \mathrm{~F}$ as a curative corrosion inhibitor for steel reinforcements in concrete, Cem. Concr. Res. 22 (1992) 869-881.

[6] K. Soeda, T. Ichimura, Present state of corrosion inhibitors in Japan, Cem. Concr. Compos. 25 (2003) 117-122.

[7] R.K. Dhir, M.A.K. El-Mohr, T.D. Dyer, Chloride binding in GGBS concrete, Cem. Concr. Res. 26 (1996) 1767-1773.

[8] G.K. Glass, N.R. Buenfeld, The presentation of the chloride threshold level for corrosion of steel in concrete, Corros. Sci. 39 (1997) 1001-1013.

[9] H. Tatematsu, T. Sasaki, Repair materials system for chloride-induced corrosion of reinforcing bars, Cem. Concr. Compos. 25 (2003) 123-129.

[10] L. Raki, J.J. Beaudoin, L. Mitchell, Layered double hydroxide-like materials: nanocomposites for use in concrete, Cem. Concr. Res. 34 (2004) 1717-1724.

[11] L. Raki, J.J. Beaudoin, Release formulation of chemical admixtures in cement and concrete, US Patent, No. US20070022916A, 2007.

[12] S. Nonaka, T. Sato, Cement modifier, Japan Patent, No. JP2001089211A, 2001.

[13] E. Tatematsu, T. Nakamura, H. Koshimizu, S. Takatsu, Chlorine ion scavenger, Japan Patent, No. JP04154648A, 1992.

[14] M. Morioka, K. Ashida, M. Handa, Cement admixture and cement composition, Japan Patent, No. JP05262546A, 1993.

[15] K. Michio, Cement mortar capable of preventing salt damage and rusting, Japan Patent, No. JP09142903A, 1997.

[16] H. Tatematsu, T. Nakamura, H. Koshimizu, T. Morishita, H. Kotaki, Cementadditive for inhibiting concrete-deterioration, US Patent, No. US5435846A, 1995.

[17] T. Sato, T. Wakabayashi, M. Shimada, Adsorption of various anions by magnesium aluminum oxide of $\left(\mathrm{Mg}_{0.7} \mathrm{Al}_{0.3} \mathrm{O}_{1.15}\right)$, Ind. Eng. Chem. Prod. Res. Dev. 25 (1986) 89-92.

[18] J.G. Nunan, P.B. Himelfarb, R.G. Herman, K. Klier, C.E. Bogdan, G.W. Simmons, Methanol synthesis catalysts based on $\mathrm{Cs} / \mathrm{Cu} / \mathrm{ZnO} / \mathrm{M}_{2} \mathrm{O}_{3}(\mathrm{M}=\mathrm{Al}, \mathrm{Cr}, \mathrm{Ga})$ : genesis from coprecipitated hydrotalcite-like precursors, solid-state chemistry, morphology, and stability, Inorg. Chem. 28 (1989) 3868-3874. 
[19] L. Lv, J. He, M. Wei, D.G. Evans, X. Duan, Uptake of chloride ion from aqueous solution by calcined layered double hydroxides: equilibrium and kinetic studies, Water Res. 40 (2006) 735-743.

[20] J. Hua, L. Lu, Chloride removal from wastewater by thermally treated hydrotalcite, Chin. J. Geochem. 25 (2006) 255-256.

[21] F.P. Glasser, J. Marchand, E. Samson, Durability of concrete - degradation phenomena involving detrimental chemical reactions, Cem. Concr. Res. 38 (2008) 226-246.

[22] V.S. Ramachandran, Possible states of chloride in the hydration of tricalcium silicate in the presence of calcium chloride, Mater. Struct. 4 (1971) 3-12.

[23] J.J. Beaudoin, V.S. Ramachandran, R.F. Feldman, Interaction of chloride and CS-H, Cem. Concr. Res. 20 (1990) 875-883.

[24] S. Yoon, J. Ha, S.R. Chae, D.A. Kilcoyne, P.J.M. Monteiro, X-ray spectromicroscopic study of interactions between $\mathrm{NaCl}$ and calcium silicate hydrates, Mag. Concr. Res. 66 (3) (2014) 141-149. Published online ahead of print.

[25] A.K. Suryavanshi, J.D. Scantlebury, S.B. Lyon, Mechanism of Friedel's salt formation in cements rich in tri-calcium aluminate, Cem. Concr. Res. 26 (1996) $717-727$.

[26] M.R. Jones, D.E. Macphee, J.A. Chudek, G. Hunter, R. Lannegrand, R. Talero, S.N. Scrimgeour, Studies using ${ }^{27}$ Al MAS NMR of AFm and AFt phases and the formation of Friedel's salt, Cem. Concr. Res. 33 (2003) 177-182.

[27] U.A. Birnin-Yauri, F.P. Glasser, Friedel's salt, $\mathrm{Ca}_{2} \mathrm{Al}(\mathrm{OH})_{6}(\mathrm{Cl}, \mathrm{OH}) \cdot 2 \mathrm{H}_{2} \mathrm{O}$ : its solid solutions and their role in chloride binding, Cem. Concr. Res. 28 (1998) 17131723.

[28] M. Balonis, B. Lothenbach, G. Le Saout, F.P. Glasser, Impact of chloride on the mineralogy of hydrated Portland cement systems, Cem. Concr. Res. 40 (2010) 1009-1022.

[29] H. Zibara, D. Hooton, K. Yamada, M.D.A. Thomas, Roles of cement mineral phases in chloride binding, Cem. Sci. Concr. Technol. 56 (2002) 384-391.

[30] H. Hirao, K. Yamada, H. Takahashi, H. Zibara, Chloride binding of cement estimated by binding isotherms of hydrates, J. Adv. Concr. Technol. 3 (2005) 77-84.

[31] J. Csizmadia, G. Balözs, F.D. Tamás, Chloride ion binding capacity of aluminoferrites, Cem. Concr. Res. 31 (2001) 577-588.

[32] V. Baroghel-Bouny, X. Wang, M. Thiery, M. Saillio, F. Barberon, Prediction of chloride binding isotherms of cementitious materials by analytical model or numerical inverse analysis, Cem. Concr. Res. 42 (9) (2012) 1207-1224.

[33] E. Samson, J. Marchand, J.L. Robert, J.P. Bournazel, Modelling ion diffusion mechanisms in porous media, Int. J. Numer. Meth. Eng. 46 (1999) 2043-2060.

[34] E. Samson, G. Lemaire, J. Marchand, J.J. Beaudoin, Modeling chemical activity effects in strong ionic solutions, Comput. Mater. Sci. 15 (1999) 285-294.

[35] E. Samson, J. Marchand, K.A. Snyder, J.J. Beaudoin, Modeling ion and fluid transport in unsaturated cement systems for isothermal conditions, Cem. Concr. Res. 35 (2005) 141-153.

[36] E. Samson, J. Marchand, Modeling the transport of ions in unsaturated cement-based materials, Comput. Struct. 85 (2007) 1740-1756.

[37] S. Yoon, S.-G. Oh, J. Ha, P.M. Monteiro, The effects of surface treatments on rapid chloride permeability tests, Mater. Chem. Phys. 135 (2012) 699-708.

[38] V. Baroghel-Bouny, M. Thiéry, X. Wang, Modelling of isothermal coupled moisture-ion transport in cementitious materials, Cem. Concr. Res. 41 (2011) 828-841.

[39] T. Luping, L.O. Nilsson, Chloride binding capacity and binding isotherms of OPC pastes and mortars, Cem. Concr. Res. 23 (1993) 247-253.

[40] E.J. Garboczi, D.P. Bentz, Computer simulation of the diffusivity of cementbased materials, J. Mater. Sci. 27 (1992) 2083-2092.
[41] T.C. Powers, T.L. Brownyard, Studies of the physical properties of hardened Portland cement paste, ACI J. Proc. 18 (1947) 101-132.

[42] D.P. Bentz, Influence of water-to-cement ratio on hydration kinetics: simple models based on spatial considerations, Cem. Concr. Res. 36 (2006) 238-244.

[43] John Crank, The Mathematics of Diffusion, Oxford University Press, 1979.

[44] L.Y. Li, C.L. Page, Modelling of electrochemical chloride extraction from concrete: influence of ionic activity coefficients, Comput. Mater. Sci. 9 (1998) 303-308.

[45] J. Wang, A.G. Kalinichev, J.E. Amonette, R.J. Kirkpatrick, Interlayer structure and dynamics of $\mathrm{Cl}$-bearing hydrotalcite: far infrared spectroscopy and molecular dynamics modeling, Am. Mineral. 88 (2003) 398-409.

[46] O.E. Gjørv, Durability and Service Life of Concrete Structures, the First Fib Congress, Japan Prestressed Concrete Engineering Association, Tokyo, 2002 pp. $1-16$.

[47] P. Lambert, C.L. Page, N.R. Short, Pore solution chemistry of the hydrated system tricalcium silicate/sodium chloride/water, Cem. Concr. Res. 15 (1985) 675-680.

[48] C. Andrade, C.L. Page, Pore solution chemistry and corrosion in hydrated cement systems containing chloride salts: a study of cation specific effects, $\mathrm{Br}$. Corros. J. 21 (1986) 49-53.

[49] R.H. Rogue, W. Lerch, Hydration of Portland cement compounds, Ind. Eng. Chem. 26 (1934) 837-847.

[50] ASTM C 1218-99, Standard Test Method for Water-Soluble Chloride in Mortar and Concrete, American Society for Testing and Materials and Structures, 2008.

[51] X. Feng, E.J. Garboczi, D.P. Bentz, P.E. Stutzman, T.O. Mason, Estimation of the degree of hydration of blended cement pastes by a scanning electron microscope point-counting procedure, Cem. Concr. Res. 34 (2004) 1787-1793.

[52] I. Langmuir, The adsorption of gases on plane surfaces of glass, mica and platinum, J. Am. Chem. Soc. 40 (1918) 1361-1403.

[53] H.M.F. Freundlich, Over the adsorption in solution, J. Phys. Chem. 57 (1906) 385-470.

[54] A.G. Kalinichev, R.J. Kirkpatrick, Molecular dynamics modeling of chloride binding to the surfaces of calcium hydroxide, hydrated calcium aluminate and calcium silicate phases, Chem. Mater. 14 (2002) 3539-3549.

[55] A.G. Kalinichev, J. Wang, R.J. Kirkpatrick, Molecular dynamics modeling of the structure, dynamics and energetics of mineral-water interfaces: application to cement materials, Cem. Concr. Res. 37 (2007) 337-347.

[56] S. Yoon, P.J. Monteiro, Molecular dynamics study of water molecules in interlayer of $14 \AA$ A. J. Adv. Concr. Technol. 11 (2013) 180-188.

[57] S. Lagergren, About the theory of so-called adsorption of soluble substances, K. Sven. Vetenskapsakad. Handl. 24 (1898) 1-39.

[58] Y.S. Ho, G. McKay, Sorption of dye from aqueous solution by peat, Chem. Eng. J. 70 (1998) 115-124.

[59] Y.S. Ho, G. McKay, D.A.J. Wase, C.F. Forster, Study of the sorption of divalent metal ions on to peat, Adsorpt. Sci. Technol. 18 (2000) 639-650.

[60] J. Zeldowitsch, Über den mechanismus der katalytischen oxydation von CO an $\mathrm{MnO}_{2}$, Acta Physicochim. U. R. S. S. 1 (1934) 364-449.

[61] Y.S. Ho, G. McKay, A comparison of chemisorption kinetic models applied to pollutant removal on various sorbents, Process Saf. Environ. Prot. 76 (1998) $332-340$

[62] P. Duan, W. Chen, J. Ma, Z. Shui, Influence of layered double hydroxides on microstructure and carbonation resistance of sulphoaluminate cement concrete, Constr. Build. Mater. 48 (2013) 601-609. 